\title{
IMPACT OF RISK FACTORS ON THE EPIDEMIOLOGICAL PREVALENCE OF GIARDIA LAMBLIA ASSEMBLAGES IN KAFRELSHEIKH GOVERNORATE, CAIRO, EGYPT \\ By \\ SALWA M. MORS ${ }^{1,2^{*}}$ AND MARWA M. I. GHALLAB ${ }^{3}$
}

Department of Medical Parasitology, Faculty of Medicine, Cairo University ${ }^{1}$, and Faculty of Medicine, Modern University for Technology and Information ${ }^{2}$, Egypt and Department of Medical Parasitology, Faculty of Medicine, Kafrelsheikh University, Egypt $^{3}$ ( ${ }^{*}$ Correspondence: smmorsy@kasralainy.edu.eg)

\begin{abstract}
Although the incidence of Giardia lamblia increased, data regarding its possible associated risk factors are scares. The study investigated the genetic diversity of humans G. lamblia positive isolates in kafrelsheikh Governorate, and the impact of multiple risk factors on prevalence. A total of 300 fecal samples were collected from patients attended Kafrelsheikh University over a period of one year. Amplification and RFLP analysis of $\beta$-giardin gene were used to identify the G. lamblia multiple assemblages.

The results showed that, PCR amplification showed 63/300 (21\%) positive samples, of them, 12 assemblages A (19.1\%) and 52 assemblages B (80.9\%). On univariate analysis, there were statistical significant correlation among giardiasis and age group, sex, hand-washing, milk type, flatulence, vomiting, and animal contact $(\mathrm{p}=0.028,0.006,0.005,0.02,0.000,0.002 \&$ 0.000 , respectively). On Multivariate logistic regression analysis showed that children from 26 years, adults ( $<18$ years), females, hand-washing, boiled milk, vomiting, flatulence and animal contact were independent risk factors for giardiasis $(\mathrm{p}=0.01,0.02,0.007,0.05,0.03$, $0.000,0.002 \& 0.000$, respectively).
\end{abstract}

Keywords: Giardia lamblia, Assemblage, Kaferelsheikh, Cairo, Risk factors.

Introduction

Giardia lamblia constitutes the most prevalence parasite infecting man, domestic and wild animals especially in developing countries with an annual rate of $10-50 \%$ or 200 million cases (Noradilah et al, 2019). Many water Giardia cyst borne outbreaks were reported (Wang et al, 2019).

According to genetic characterization of different genetic markers (mall subunit ribosomal RNA (ssurRNA), the glutamate dehydrogenase (gdh), $\beta$-giardin (bg), triose phosphate isomerise (tpi), elongation factor 1alpha (ef-1 $\alpha$ ), and GLORF-C4 genes), $G$. lamblia is a multispecies complex comprised of at least eight different genetic assemblages (A-H) (Rehbein et al, 2019). The majority of human infection was due to zoonotic assemblages A that could infect other mammals and B was mainly reported in man \& a small number of animal species, but other assemblages were host specific (Feng et al, 2011). Data were lacking about the risk factors affecting the genotypic epidemiology as seasonality, age, sex, consumed water, animal contact and clinical presentations (Asher et al, 2016).

This study aimed to investigate the genetic diversity of $G$. lamblia positive isolates in humans in Kafrelsheikh Governorate, and to evaluate demographic, environmental and clinical data on the genotypic prevalence of different Giardia assemblages.

\section{Materials and Methods}

Study population: after Kafrelsheikh Faculty of Medicine Institutional Board Review and calculation of sample size, a cross sectional study was done over 300 patients of both sexes aged from 1 to 60 years old with either diarrhea and/or associated with abdominal pain, vomiting, fever or flatulence and not received any antidiarrheal drug. Patients attended outpatient clinics in Kafrelsheikh University Hospitals January 2018 to January 2019 (150 in dry season and others in wet season). They were classified by age according to into 5 categories: infant $<2$ years, 2-6 years early childhood, 6-12 years 
late childhood, 12-18 years adolescent and adult $>18$ years. A single fecal sample was collected from each one with recordation to demographic, clinical and environmental data using a designed questionnaire.

Coproscopy of stool samples: All samples were examined microscopically fresh and fixed with sodium acetate acetic acid formalin (SAF) and the others were kept at $-20^{\circ} \mathrm{C}$ for copro- PCR assays Garcia 2007).

Copro DNA extraction and amplification: Extraction of genomic DNA was done using Favor Prep stool DNA isolation Mini Kit (Favorgen Biotech corporation ping-Tung 908, Taiwan, Cat. No. FASTI001) according to manufacturer's instruction with modification in the form of thermal cell disruption (shock): samples were thrown in liquid nitrogen for $5 \mathrm{~min}$. and then immediately transferred into water bath $95^{\circ} \mathrm{C}$ for $5 \mathrm{~min}$. (repeated for 10 cycles). Amplification $\beta$-giardin gene was done (Naguib et al, 2018) with modification of the annealing temperature to $75^{\circ} \mathrm{C}$ in primary reaction and $55^{\circ} \mathrm{C}$ for nested one. Positive and negative controls are incorporated in each reaction. Assemblage specific pattern were obtained by digestion of the amplified nested PR products by Hae III restriction enzyme.

Statistical analysis: Data were tabulated

Table 1: Prevalence \& univariate analysis of possible risk factors associated with Giardia lamblia among group (n=300).

\begin{tabular}{|c|c|c|c|c|}
\hline & & Giardia positive $(\mathrm{N}=63)$ & Giardia negative $(\mathrm{N}=237)$ & $\mathrm{P}$ value \\
\hline \multirow{5}{*}{ Age group } & Infant $(<2 \mathrm{Y})$ & $6(2 \%)$ & $46(15.3 \%)$ & \multirow{5}{*}{0.028} \\
\hline & Early childhood (2-6 Y) & $32(10.7 \%)$ & $88(29.3 \%)$ & \\
\hline & Late childhood (6-12Y) & $3(1 \%)$ & $8(2.7 \%)$ & \\
\hline & Adolescence(12-18 Y) & $11(3.7 \%)$ & $24(8 \%)$ & \\
\hline & Adult ( $>18 Y)$ & $11(3.7 \%)$ & $71(23.6 \%)$ & \\
\hline \multirow{2}{*}{ Gender } & Female & $43(14.3 \%)$ & $116(38.7 \%)$ & \multirow{2}{*}{0.006} \\
\hline & Male & $20(6.7 \%)$ & $121(40.3 \%)$ & \\
\hline \multirow{6}{*}{$\begin{array}{c}\text { Associated } \\
\text { complaint }\end{array}$} & Weight loss & $18(28.5 \%)$ & $282(17.5 \%)$ & 0.161 \\
\hline & Loss of appetite & $32(50.7 \%)$ & $268(49.7 \%)$ & 0.35 \\
\hline & Fever & $17(5.7 \%)$ & $283(83 \%)$ & 0.14 \\
\hline & Abdominal pain & $58(19.3 \%)$ & $242(80.7 \%)$ & 0.099 \\
\hline & Flatulence & $59(19.6 \%)$ & $241(80.4 \%)$ & 0.000 \\
\hline & Vomiting & $40(13.3 \%)$ & $260(86.7 \%)$ & 0.002 \\
\hline Animal contact & Yes & $28(9.3 \%)$ & $272(90.7 \%)$ & 0.000 \\
\hline \multirow{2}{*}{ Hand washing } & Yes & $53(17.7 \%)$ & $199(66.3 \%)$ & \multirow{2}{*}{0.005} \\
\hline & $\mathrm{NO}$ & $10(3.3 \%)$ & $38(12.7 \%)$ & \\
\hline \multirow{2}{*}{ Milk type } & Boiled & $56(18.7 \%)$ & $182(60.7 \%)$ & \multirow{2}{*}{0.028} \\
\hline & Pasteurized & $7(2.3 \%)$ & $55(18.3 \%)$ & \\
\hline \multirow{2}{*}{ Season } & Dry & $29(9.7 \%)$ & $121(40.3 \%)$ & \multirow{2}{*}{0.47} \\
\hline & Wet & $34(11.3 \%)$ & $116(38.7 \%)$ & \\
\hline
\end{tabular}

*Data presented as No., percentages and $\mathrm{P}$ value $<0.05$. 
Table 2: Multivariate analysis of possible associated risk factors.

\begin{tabular}{|c|l|c|c|c|}
\hline \multicolumn{1}{|c|}{ Table 2: Multivariate analysis of possible associated risk factors. } \\
\hline \multirow{4}{*}{ Age group } & \multicolumn{1}{|c|}{ Items } & P value & OR & CI \\
\hline & Infant & 0.75 & 0.84 & $2.91-2.43$ \\
\cline { 2 - 5 } & Early childhood & 0.01 & 2.6 & $1.22-5.75$ \\
\cline { 2 - 5 } & Late childhood & 0.68 & 1.29 & $0.37-4.49$ \\
\cline { 2 - 5 } & Adolescence & 0.23 & 2.42 & $0.55-10.53$ \\
\cline { 2 - 5 } & Adult & 0.02 & 2.95 & $1.13-7.69$ \\
\hline Sex & Female/ male & 0.007 & 2.24 & $1.24-4.03$ \\
\hline \multirow{2}{*}{ Associated complaint } & Flatulence & 0.000 & 0.08 & $0.02-0.228$ \\
\cline { 2 - 5 } & Vomiting & 0.002 & 0.4 & $0.22-0.72$ \\
\hline Animal contact & Yes & 0.000 & 0.23 & $0.12-0.42$ \\
\hline Hand washing & Yes & 0.005 & 0.24 & $0.09-0.65$ \\
\hline Milk type & Boiled /Pasteurized & 0.03 & 2.4 & $1.06-5.73$ \\
\hline
\end{tabular}

Table 3: Distribution of Giardia assemblages in comparison to potential risk factor

\begin{tabular}{|c|c|c|c|c|}
\hline & Items & Assemblage A $(\mathrm{N}=12)$ & Assemblage $\mathrm{B}(\mathrm{N}=51)$ & P value \\
\hline \multirow{5}{*}{ Age group } & Infant & 0 & 6 & \multirow{5}{*}{0.73} \\
\hline & Early childhood & 7 & 25 & \\
\hline & Late childhood & 1 & 2 & \\
\hline & Adolescence & 2 & 9 & \\
\hline & Adult & 2 & 9 & \\
\hline \multirow[b]{2}{*}{ Gender } & Female & 8 & 35 & \multirow{2}{*}{0.89} \\
\hline & Male & 4 & 16 & \\
\hline \multirow{6}{*}{$\begin{array}{c}\text { Associated } \\
\text { complaint }\end{array}$} & Weight loss & 5 & 13 & 0.26 \\
\hline & Loss of appetite & 6 & 26 & 0.95 \\
\hline & Fever & 2 & 15 & 0.35 \\
\hline & Abdominal pain & 12 & 46 & 0.25 \\
\hline & Flatulence & 10 & 49 & 0.10 \\
\hline & Vomiting & 9 & 31 & 0.37 \\
\hline Animal contact & Yes & 3 & 25 & 0.12 \\
\hline \multirow{2}{*}{ Hand washing } & Yes & 10 & 43 & \multirow{2}{*}{0.99} \\
\hline & $\mathrm{NO}$ & 2 & 8 & \\
\hline \multirow{2}{*}{ Milk type } & Boiled & 9 & 47 & \multirow{2}{*}{0.11} \\
\hline & Pasteurized & 3 & 7 & \\
\hline \multirow{2}{*}{ Season } & Dry & 11 & 18 & \multirow{2}{*}{0.87} \\
\hline & Wet & 1 & 33 & \\
\hline
\end{tabular}

\section{Discussion}

In the present study, genotyping results revealed the occurrence of both assemblages $\mathrm{B}$ and $\mathrm{A}$ with predominance of $\mathrm{B}$ suggesting that the infection is primarily anthroponotic which may be through non hygienic personal practices including feeding habits and inefficient environmental sanitation.

The current study showed that early childhood had higher prevalence of giardiasis with statistical significance between age groups and giardiasis $(P$ value $=0.028)$. Similar results were obtained in one previous study in Egypt, where children had a higher frequency of assemblage B (24/34 or $70.6 \%)$ than assemblage A (10/34 or $29.4 \%)$, while adults had a similar frequency of both assemblages $(12 / 26$ or $46.2 \%$ \& $14 / 26$ or $53.8 \%$, respectively) (Mohammad et al. 2011). This agreed with Choy et al. (2014) and El-Badry et al. (2017). This may be attributed to the higher risk of exposure of young children to a wide range of infectious sources that could be due to lower personal hygienic standards when compared to the older children or adults. This was in contrary to Ignatius et al. 2012 who documented that there was no correlation between age and giardiasis.

In this study, $49 \%(25 / 51)$ of Giardia children were infected with assemblage B, compared with $17.6 \%(9 / 51)$ in both adolescence and adults. Similarly, in on previous Egyptian study children had a higher frequency of assemblage $\mathrm{B}$ than assemblage $\mathrm{A}$, but adults had same frequency of both assemblages (El Basha et al, 2016). Also, Ignatius et al. (2012) found that children had a higher frequency of assemblage B (24/34 or $70.6 \%)$ than assemblage A (10/34 or $29.4 \%)$, while 
adults had a same frequency of both assemblages $(12 / 26$ or $46.2 \% \& 14 / 26$ or $53.8 \%$, respectively)

In contrast, in United Kingdom in which assemblages A \& B were equally distributed in children of 0-9 years, assemblage B was more predominant in adults of 30-49 years, and assemblage $\mathrm{A}$ was more common in adults $>50$ years (Minetti et al, 2015). This indicated that dominance of $G$. lamblia genotypes could be changed in humans over age reflecting the differences in exposures and /or the development of acquired immunity.

Variation in sex distribution was highly significant $(\mathrm{P}=0.006)$. This agreed with Duldova et al. (2012) who found a higher prevalence in females than males, and added that females caring for their children or working in care-day centers or nurseries. But, this disagreed with Julio et al. (2012) and De Lucio et al. (2015) who found a higher giardiasis incidence in males than in females.

Baldursson and Karanis (2011) considered giardiasis the most common causes of waterborne diseases outbreaks worldwide.

None of the drinking water sources in the study was significantly associated with the development of giardiasis risk $(\mathrm{P}=0.464)$. This may be attributed to the fact that most of studied individuals mainly depended on tap water as the main source of water supply. This agreed with Okojokwu et al. (2014). Others reported significant association between type of water and giardiasis (Choy et al, 2014; Osman et al, 2016).

In this study, association was between animal contact and giardiasis $(\mathrm{P}=0.000)$. Also, Júlio et al. (2012) showed a positive association regarding the giardiasis pre-valence and the animal contact. But, others did not find association between animal contact and giardiasis (Hunter et al, 2005).

In the present study, flatulence was the most common clinical symptom followed by abdominal pain and then vomiting, but there was significant correlation between the presence of flatulence, vomiting and giardiasis $(\mathrm{P}=0.000 \& 0.002$ respectively). This agr- eed with Lebbad et al. (2011) who found that flatulence was significantly commonly associated with giardiasis. But, Torabi et al. (2014) did not find any association between flatulence and giardiasis $(\mathrm{P}=0.925)$

In the present study, there was no correlation between infections in dry and/or wet seasons. But, Noradilah et al. (2019) found that seasonality played a major role in protozoa mainly in the river water during the dry season, and using infected untreated water or water-related activities during this season reduce the burden of $G$. lamblia infection.

The present study showed no significant difference between clinical symptoms and infection with assemblages A \& B. This may be related to multiple factors affected variability of $G$. lamblia clinical outcomes genotypes as: hosts, nutrition, immunity, and pathogenicity. The present data agreed with Ismail et al. (2016) who found many variations in socioeconomic status in same geographical areas and population densities played a major role in giadiasis prevalence.

\section{Conclusion}

A higher giardiasis incidence was found in Kafrelsheikh Governorate. Predominance of assemblage B indicated that infection was mostly anthroponotic. Children aged from 2-6 years, adults $<18$ years, females, hand-washing, boiled milk, vomiting, flatulence and animal contact were all independent risk factors.

\section{Acknowledgements}

The authors would like to thank Dr. Diaa Eldin Taha, Urosurgery Department, Kafrelsheikh University, Egypt for his kind help.

\section{References}

Asher AJ, Hose G, Power ML, 2016: Giardiasis in NSW, identification of Giardia duodenalis assemblages contributing to human and cattle cases, and an epidemiological assessment of sporadic human giardiasis. Infect. Genet. Evol. 44: 157-61.

Baldursson S, Karanis P, 2011: Waterborne transmission of protozoan parasites, review of worldwide outbreaks - an update 2004-2010. Water Res. 45:6603-14.

Choy, SH, Al-Mekhlafi, HM, Mahdy, MAK, Nasr, NN, Sulaiman, M, et al, 2014: Prevalence and associated risk factors of Giardia in- 
fection among indigenous communities in Rural Malaysia. Sci. Rep. 4:6909.

De Lucio, A, Martinez-Ruiz, R, Merino, FJ, Bailo, B, Aguilera, M, et al, 2015: Molecular geno-typing of Giardia duodenalis isolates from symptomatic individuals attending two major public hospitals in Madrid, Spain. PLoS One 10, 12:e143981.

Duldova, A, Juris, P, Jurisova, S, Jarcuska, P, Krcmery, V, 2012: Epidemiology and geographical distribution of gastrointestinal parasitic infection in humans in Slovakia. Helminthologia 53, 4:309-17.

El Basha, NR, Zaki, MM, Hassanin, OM, Rehan, MK, Omran, D, 2016: Giardia assemblages A \& B in diarrheic patients: a comparative study in Egyptian children and adults. J. Parasitol. 102:69-74.

El-Badry, AA, Mohammed, AF, Abdul Gawad E, 2017: Predominance of Giardia intestinalis assemblage B in diarrhoeic children in Sharkia, Egypt. PUJ 10:39-43.

Espelage, W, Heiden, MAD, Stark, K, Alpers, K, 2010: Characteristics and risk factors for symptomatic Giardia lamblia infections in Germany. BMC Pub. Hlth. 10:41.

Feng Y, Xiao L, 2011: Zoonotic potential and molecular epidemiology of Giardia species and giardiasis. Clin. Microbiol. Rev. 24:110-40.

Garcia, LS, 2007: Diagnostic Medical Parasitology, 5th ed. ASM Press, Washington D. C.

Hunter PR, Thompson RC, 2005: The zoonotic transmission of Giardia and Cryptosporidium. Int. J. Parasitol. 35, 11/12:1181-90.

Ignatius, R, Gahutu, JB, Klotz, C, Steininger, C, Shyirambere, C, et al, 2012: High prevalence of Giardia duodenalis Assemblage B infection $\&$ association with underweight in Rwandan children. PLoS Negl. Trop. Dis. 6:e1677.

Ismail MAM, El-Akkad, DMH, Rizk, EMA, El-Askary, HME, El-Badry, AA, 2016: Molecular seasonality of Giardia lamblia in a cohort of Egyptian children: a circannual pattern. Parasitol Res. 115:4221-7.

Júlio, C, Vilares, A, Oleastro, M, Ferreira, I, Gomes, S, et al, 2012: Prevalence and risk factors for Giardia duodenalis infection among children: A case study in Portugal. Parasit. Vector 5:22-9.

Lebbad, M, Peterson, I, Karlsson, L, Kleiven, SB, Andersson, JO, et al, 2011: Multi-locus ge- no-typing of human Giardia isolates suggests limited zoonotic transmission and association between assemblage B and flatulence in children. PLoS Negl. Trop. Dis. 5, 8:e1262.

Minetti, C, Lamden, K, Durband, C, Cheesbrough, J, Fox, A, et al, 2015: Determination of Giardia duodenalis assemblages and multi-locus genotypes in patients with sporadic giardiasis from England. Parasit. Vector 8:444-8.

Mohammad, KA, 2011: Detection of human intestinal protozoa by using multiplex allele specific polymerase chain reaction (MAS-PCR). ZUMJ 19, 6:556-68.

Naguib, D, El-Gohary, A, Roellig, D, Mohamed, A, Arafat, N, et al, 2018: Molecular characterization of Cryptosporidium spp. \& Giardia duodenalis in children in Egypt. Parasit. Vector 403:11-13.

Nazeer, JT, Khalifa, KE, Thien, HV, EISibaei, MM, Abdel-Hamid, MY, et al, 2013: Use of multiplex real-time PCR for detection of common diarrhea causing protozoan parasites in Egypt. Parasitol. Res. 2:595-601.

Noradilah SA, Moktar N, Lee, IL, Salleh, F M, Anuar, TS, 2019: Impact of seasonality on the prevalence and risk factors of Giardia lamblia infections among the aborigines. Asian Pac. J. Trop. Med. 12:315-20.

Okojokwu, OJ, Inabo, HI, Yakubu, SE, Okubanjo, OO, 2014: Cryptosporidium infection among patients presenting with diarrhea in Kaduna State, Nigeria. Researcher 6, 12:14-7.

Osman, M, El Safadi, D, Cian, A, Benamrouz, S, Nourrisson, C, et al, 2016: Prevalence and risk factors for intestinal protozoan infections with Cryptosporidium, Giardia, Blastocystis and Dientamoeba among school children in Tripoli, Lebanon. PLoS Negl. Trop. Dis. 10, 3:e4496.

Rehbein, S, Klotz C, Ignatius, R, Müller, E, Aebischer A, et al, 2019: Giardia duodenalis in small animals and their owners in Germany: A pilot study. Zoonoses Pub. Hlth. 66, 1:117-24.

Torabi, Z, Niksirat. A, Mazloomzadeh, S, Ahmadiafshar, A, 2014: Consistency of direct microscopic examination and ELISA in detection of Giardia in stool specimen among children. Asian Pac. J. Trop. Dis. 4, 2:S725-7.

Wang, Y, Gonzalez-Moreno, O, Roellig, DM, Oliver, L, Huguet, J, et al, 2019: Epidemiological distribution of genotypes of Giardia duodenalis in humans in Spain. Parasit. Vector 12:43-8. 